\title{
La vida práctica en Montaigne y Descartes
}

\section{The practical life in Montaigne and Descartes}

\author{
RAQUEL LÁZARO \\ Universidad de Navarra
}

Recibido: 10-04-2007 Aprobado definitivamente: 12-06-2007

\section{RESUMEN}

El estudio se centra en la filosofía práctica cartesiana: la dimensión técnica y la moral. Una parte de su filosofía muchas veces poco estudiada. A lo largo del Discurso del Método, Descartes parece dialogar con Michel de Montaigne para superar su posición escéptica. Lo consigue desde el punto de vista teórico, pero no en relación a la acción moral. En ese ámbito, Descartes lejos de alejarse de las posiciones montañistas, las reproduce. Las reglas de la moral provisional ya están en Montaigne y, como él, Descartes se tiene que conformar con lo probable en la acción moral.

\author{
PALABRAS CLAVE \\ DESCARTES, MONTAIGNE, ÁMBITO TEÓRICO, ÁMBITO PRÁCTICO
}

\section{ABSTRACT}

This study is about Descartes' philosophy: both its technical dimension and morality. Little attention has been paid to this part of his philosophy. Along the Discourse on Method, Descartes seems to speak with Michel de Montaigne with a view to overcome his sceptical position. He reaches this goal from the theoretical point of view, but not in the practical realm. In this area Descartes, far from moving away from Montaigne's position, reproduces it. The rules of provisional morality are already in Montaigne and, like him, Descartes has to conform to a probabilistic approach in the moral action.

\section{KEY WORDS}

DESCARTES, MONTAIGNE, THEORETICAL REALM, PRACTICAL REALM 
EL APRENDER A CONDUCIRSE EN LA VIDA ha sido una preocupación constante a lo largo de la historia de la filosofía, pero ha habido épocas en las cuales se ha acentuado especialmente. Una de ellas ha sido la modernidad. Tanto racionalistas como empiristas buscan alcanzar algunas reglas que sirvan de medida para la acción, o al menos ensayar algún tipo de sabiduría o ciencia que sea eminentemente práctica. Éste fue en concreto el objetivo último de la reflexión filosófica que se lleva a cabo en los Ensayos de Michel de Montaigne (Chamizo, 1988, p. 73), obra con la que se inicia el giro moderno hacia la subjetividad y que tanto influyó en los grandes pensadores del siglo XVII francés, muy especialmente en Descartes, quien estuvo interesado por la filosofía práctica desde su juventud. De todos es conocido como cifraba el fruto último de su filosofía precisamente en los grandes avances que se podrían lograr en la mecánica, en la medicina y en la moral. Ya Gilson se hace eco de la moral provisional en su pormenorizado comentario al Discurso del Método (1976, pp. 229-282). El profesor Grimaldi ha desarrollado su amplia obra sobre Descartes entorno a la vertiente práctica. Una perspectiva parecida se percibe en el estudio de Kennington.

En ocasiones se ha pensado que Descartes dedicó más tiempo y parte de su obra a la investigación de los fundamentos teóricos de su sistema que a la parte práctica que su filosofía añoraba alcanzar. El Discurso del Método, las Meditaciones y los Principios, han acaparado la atención de los que se acercaban a Descartes. Las Pasiones del Alma -última obra publicada por el autor en 1649-, a veces ha sido considerada una obra menor. Sin embargo, no era eso lo que pensaba el propio Descartes, tal como se lo confiesa a Chanut en una carta fechada el 20 de noviembre de 1647. Le confía que es esencial conocer «su pequeño tratado sobre las pasiones» (Correspondance, AT, V, p. 87), ya que son principalmente ellas las que hay que tratar de conocer para poder alcanzar el soberano bien.

Los contemporáneos al autor del Discurso se ocuparon ampliamente de la metafísica cartesiana, a la que realmente Descartes dedicó muchas páginas. Lo interesante es preguntarse ¿por qué tanta dedicación a algo que no constituía su gran preocupación? Todo apunta a pensar que Descartes buscaba una seguridad práctica que no acabó de encontrar, pero que de alguna manera debería seguirse de su proyecto de ciencia única e infalible. El autor del Discurso insistía en el fundamento teórico que había de sostener la vida práctica, pero ésta última aparecía finalmente en sintonía con un saber cargado de probabilidad e incertidumbre, frente a la certeza absoluta que la metafísica asegura para sus verdades. Es ahí precisamente, en el saber práctico, donde aflora la deuda que Descartes tiene con Montaigne, tal como ha sido puesto de manifiesto por estudiosos cartesianos y montañistas. La moral provisional cartesiana es prácticamente la misma que la montañista (Chamizo, 1984, pp. 213 y 239).

Es Gilson uno de los primeros en advertirnos que el ideal mismo de alcanzar una sabiduría puramente humana es un legado heredado por Descartes a 
partir del estoicismo cristiano renacentista y de Montaigne, de modo que antes de encontrarse con Beeckman, entrará en un período de incertidumbre análogo al escepticismo de Montaigne (Gilson, 1976, pp. 93 y 139), quién abrió una escisión importante entre ciencia y sabiduría, divorcio que Descartes intentará reparar hasta hacer de ambas una sola cosa. Si la ciencia era un intento de saber acerca del mundo y la sabiduría una especie de arte para dirigir la acción humana, Descartes intentará unificar ambas en un solo saber ejercido por un único sujeto cognoscente, a saber, el cogito. Se trata de ver hasta qué punto ese intento iba a ser viable.

Montaigne y Descartes tenían puntos en común. A ambos les unía su amor a la verdad y el afán de buscarla (Chamizo, 1982, p. 74). Pero, el ensayo montañista revela a su autor que la verdad trasciende la capacidad humana; el hombre es el eterno buscador de una verdad siempre inalcanzable. Mientras que el método cartesiano permite a su autor comprender que la verdad no está más allá de nuestras posibilidades, el sujeto cognoscente llega a poseerla con seguridad. Lo epistemológico en Descartes es garantía de un saber metafísico evidente. Montaigne, en cambio, toma como punto central para su obra el «conócete a ti mismo», pero ese conocimiento se resuelve en experiencia vivida, en la aceptación de una particularidad que no puede trascender universalmente sus propios límites y que lejos de afirmarse como realidad substante, se conforma con ser un yo que siempre resulta extraño a sí mismo y en continuo movimiento (Navarro 2005, p. 135).

Si la contradicción y el movimiento son esencia de la realidad, Montaigne habrá de aprender a conducirse sabiéndose él mismo contradicción, luego no se trata de superarla definitivamente, sino de que la condición humana no impida el ejercicio mismo de la vida. Se trata de vivir a pesar de nuestra mala y pésima condición. Es a esa supuesta esencia a la que Descartes de ninguna manera quiere plegarse. Piensa que sí se puede superar la contradicción, pues si bien la experiencia confirma una y otra vez lo cambiante que es todo, comenzando por la propia opinión humana y los discursos de la razón acerca de la realidad, el hecho de que haya un sujeto capaz de saber que duda y que se contradice ya le da una cierta ventaja sobre ese saber dudoso y contradictorio. Si el yo montañista ha de estar sujeto a los límites de su particularidad contradictoria, el sujeto cartesiano se sitúa por encima de esos límites y se descubre a sí mismo como realidad substante primera e idéntica en el orden del conocimiento a pesar de la variedad de sus percepciones.

Luego, en el ejercicio de la duda Descartes alcanza algo muy distinto a lo que Montaigne nos ofrece. Para Montaigne el escepticismo es un producto de la vida (Casals, 1986, p. 66); en cambio, para Descartes la salida del escepticismo es posible y permite vivir la vida con seguridad, la condición es que haya método, porque en ese caso a partir de la duda se revelan las primeras verdades infalibles 
descubiertas: el cogito y Dios, verdades a partir de las cuales se reconstruye todo el edificio del saber hasta alcanzar el más alto grado de conocimiento de modo claro y distinto, es decir, verdadero. Si el hombre no decae en la aplicación de ese método, entonces todo el edificio del saber será una ciencia única cuyo fruto más sabroso será aprender lo más útil para la vida. En la sexta parte del Discurso Descartes parece comprometerse con una dedicación completa a ese proyecto, que tendrá dos marcas distintivas: la verdad y la utilidad. Ahora bien, esas dos notas se corresponden a mundos distintos: la verdad es lo propio de lo teórico, mientras que la utilidad sirve de medida para el mundo práctico. Quizá por ello Descartes nos advierta que el objetivo primero sea el cuidado y la conservación de la buena salud, puesto que es el primer bien útil de esta vida, base de todos los demás bienes, que se seguirán de la buena aplicación de su método. Sin embargo, Descartes no parece retomar su interés efectivo por la medicina hasta el final de su vida y gracias a la princesa Elisabeth. Ella logra que Descartes nos hable de la moral, y también gracias a ella sabemos que la moral provisional de 1637 -expuesta en el Discurso- es la misma que la de 1645 -expresada en las cartas. Es decir, la moral provisional es la moral definitiva. Ahora bien, la moral en tanto que regida por la utilidad, tiene poco que ver con la verdad que gobierna el mundo metafísico.

Dado que lo más útil y necesario para la vida es conservar la salud, el estudio de la moral, que se encarga de cómo hemos de dirigir nuestra acción, ha de comenzar por lo físico. No podría ser de otro modo. La moral dice relación no al cogito, sino al hombre, esto es, a la unión de alma y cuerpo. La tarea propia de aquel, como sustancia pensante independiente del cuerpo, es la metafísica; pero tratar de moral es hablar de la unión de alma y cuerpo, por eso la física tiene que estar presente: hay que ocuparse también de la res extensa. Eso explica que Descartes continúe en el Tratado de las Pasiones el proyecto que nos enunció en la última parte del Discurso, ahora bien: ¿por qué tanta demora en ese proyecto?, ¿por qué tanta resistencia a hablar de lo práctico que parece culminarlo?, ¿qué ha ocurrido desde que lo enunciara en 1637? Según Alquié, Descartes al descubrir la condición metafísica del hombre (Alquié, 1950) se vio obligado a insistir en la metafísica. Grimaldi (1988), en cambio, piensa que cuando Descartes descubre la libertad gracias a la moral provisional, el cogito cae en la cuenta de cuál es su auténtica verdad, lo cual hace tambalear todo ese proyecto de ciencia única e infalible que Descartes había imaginado.

Interesa no pasar por alto que la moral provisional esté enunciada en la tercera parte del Discurso, sin embargo fue lo último que escribió Descartes antes de su publicación en 1637. El editor, para evitar que Descartes fuese acusado de ser un escéptico, le sugirió escribir algo que sirviese de antídoto a la duda. Descartes en ese momento tomó en cuenta todo lo que había desechado hasta entonces en las Reglas y en la segunda parte del Discurso para asegurar 
la eficacia del método: lo probable, lo verosímil, lo contingente, lo sensible. Es decir, lo que había sido expulsado del orden teórico, es reintroducido en el orden práctico (Gilson, 1976, p. 245). El padre del racionalismo parecía pasarse a las filas empiristas. Quizá por ello Laporte califica a Descartes de empirista radical e integral (Laporte, 1988, p. 477). En esa línea, Kennington afirma que el fundador del racionalismo moderno, no era él mismo un racionalista (2004, p. 79).

Existen dos parámetros distintos en la filosofía cartesiana: el del mundo teórico y el del mundo práctico. En el primero la aplicación del método se hace con las verdades metafísicas, las matemáticas y los primeros postulados de la física, es decir, se alcanza lo necesario y evidente, lo absolutamente cierto e indubitable. En cambio, en el mundo práctico, la aplicación del método no lleva a los mismos resultados, pues en los asuntos de la vida hace falta contar con lo corporal, es decir, no con conocimientos claros y distintos, sino con los oscuros y confusos, pues tal es la condición de lo que procede de la experiencia sensible, con la que necesariamente hay que contar, puesto que la moral atañe a la unión, no tan sólo a la res cogitans. ¿A qué obedece esta especie de esquizofrenia cartesiana (Nájera, 2003, p. 27)?, ¿no introduce ese doble parámetro una escisión en la soñada ciencia única? Eso es lo que nos proponemos examinar a continuación, partiendo de la deuda que Descartes tiene con Michel de Montaigne.

\section{LOS ENSAYOS Y EL DISCURSO}

Descartes conocía perfectamente el contenido de los Ensayos. En ellos se refleja muy bien el tenor filosófico e histórico de la época: escepticismo, deísmo y librepensamiento protagonizan el siglo XVII. Montaigne había sido el máximo exponente del pensar escéptico a finales del XVI. El anonadamiento humano hacía posible la comparecencia de lo divino, Dios era el único ser verdaderamente libre de contradicción, el ser eterno que se identificaba plenamente con esa verdad que resultaba inalcanzable para el hombre. Ahora bien, ese pulso que Montaigne parecía mantener con el epicureismo -sobre todo en el tercer libro de los Ensayos-, hizo que algunos librepensadores le tomaran como estandarte de su propia causa. Sin embargo, Montaigne andaba en su obra el camino del escepticismo fideísta.

Ahora bien, ese propósito no resultaba obvio para todos. Garasse y Mersenne le atacaban. Saint-Cyran le defendía. Garasse opinaba que el escepticismo de corte pirrónico de Montaigne era un disfraz de ateísmo. En cambio, Saint Cyran, principal representante del jansenismo francés de la primera mitad del XVII -más teológico que el que vendría después- veía en Montaigne un apologista del cristianismo, una sabiduría que hacía frente a la arrogancia y autosu- 
ficiencia estoicas (Gouhier, 1987, p. 84). Era preciso mostrar toda la falibilidad y miseria humana para que el hombre abandonara el infundado orgullo al que le conducía el ejercicio de su razón y pudiera confiar en la sabiduría que sólo la fe proporciona. La nulidad del hombre comparecía sin dificultad cuando se le miraba desnudo de toda ayuda divina, sin la gracia. Sólo esa conciencia de «nada» capacitaba al hombre para un adecuado reconocimiento del verdadero alcance de su saber.

Lo importante ahora es destacar que no sólo Descartes conoce la obra de Montaigne, sino que además en lugar de abandonar su postura moral, la reintroduce y defiende, aunque lo haga en un marco filosófico más amplio, el que él mismo ha inaugurado con su método. De ahí que se pueda afirmar con Faye (1998, p. 295), que si bien Descartes supondrá una revolución en el mundo científico, no ocurre así en el mundo moral, que emerge en continuidad con la sabiduría de Montaigne y de su discípulo Charron -que también conocía Descartes. Con la salvedad de que lo práctico en Descartes se refiere a lo técnico y a lo moral, cosa que no ocurría en los autores anteriores. Pero, por lo que respecta a la moral, el probabilismo es terreno común a todos ellos. No es posible un conocimiento científico, esto es, claro y distinto, evidente, por lo que se refiere a la moral.

El Discurso es la respuesta a los Ensayos. Son muchos los autores que lo avalan. Leon Brunschvicg piensa que Descartes emprende esa respuesta a Montaigne; su influencia es clara y Descartes, vuelto al moralista francés, va a intentar una conquista positiva de los tesoros que Montaigne esconde (1945, pp. 97, 106 y 108). Para Armogathe: «La publicación del Discurso del Método en 1637 marcaba el alba de la edad moderna, al precio de algunos clichés: el método, la duda, el uso de la razón, la preocupación por las ideas claras y distintas. Este lugar común de un cartesianismo sin padre ni madre ha sobrevivido a todas las rectificaciones, y el mito de la ruptura radical persiste, al precio de múltiples olvidos, para comenzar por el contenido de los Ensayos que acompaña el Discurso y que ilustran el método» (2000, p. 1). Chamizo señala que Descartes acentúo tanto que él hacía algo nuevo, que no parecía admitir ninguna deuda entre él y sus predecesores más inmediatos, o si acaso tal deuda era sólo negativa, puesto que el autor del Discurso venía a «eliminar los errores y prejuicios de los filósofos del pasado» (1988, p. 61). Lemaire, habla de Montaigne como el precursor de Descartes (1992, p. 7). Según Toulmin tanto Descartes como Pascal se vieron fascinados por Montaigne, cuyos Ensayos Descartes estudió en la Flèche (2001, p. 75). El Discurso es el libro más montañista de Descartes y el que le permite construir una filosofía contra Montaigne, sostiene Melehy (1997, p. 96). La influencia de Montaigne en Descartes la deja sentir RodisLewis principalmente a través de Pierre Charron, cuya obra, La Sagesse, llega a Descartes en 1619, regalo de un jesuita (1995, pp. 71-76; Thweatt, 1980, p. 19.). 
Gadofre señala que es entre 1618 y 1628 cuando más se deja sentir la influencia montañista en Descartes (1987, p. 27).

Montaigne escribe sus Ensayos de modo autobiográfico, y así es como está redactado el Discurso. Ambas obras están escritas en francés y dirigidas al gran público. Montaigne advierte que no quiere instruir a nadie y en ese mismo punto coincide con él Descartes, quien no parece desear una reforma del saber en general, sino del suyo. ${ }^{1}$ Los dos autores quieren que la educación sea fruto de un pensamiento ejercido libremente y no tan sólo resultado de lo aprendido de memoria, donde se repite lo que alguna supuesta autoridad externa a la propia razón haya enseñado como canónico y definitivo. Montaigne además quiere evitar la esterilidad a la que conduce -según él- la metafísica (Llinàs, 1998, p. 290).

Tanto Descartes como Montaigne han buscado en la poesía, en la historia, y en la filosofía el cómo conducirse en la acción. Sin embargo, esas artes les han mostrado lo variado que son el discurrir y el actuar humanos. Nuestros autores han viajado por el mundo, esa escuela tan recomendada por Montaigne. Los viajes -algunos de ellos a través de los libros en el caso de Montaigne (Navarro, 2005, p. 197)- les han instruido en una sabiduría empírica irrefutable: la enorme diversidad de normas y costumbres que existen entre los hombres. Buscan la unidad de la diversidad, pero ¿dónde encontrarla? Deciden volverse hacia el único objeto que merece la pena ser estudiado y cuyo camino casi no se ha emprendido: el yo. No hay norma común, ni medida adecuada para tanta variedad. El concepto de naturaleza, como medida universal y común de lo humano es abandonado tanto por Montaigne como por Descartes. El yo moderno inicia su andadura.

\section{El yo en Montaigne y en Descartes}

El yo montañista exige un retiro para poder conocerse. Una vez en él -los años que Montaigne pasó en la torre de su castillo- lo que llega a saber de sí es aún más contradictorio que lo que conocía en medio de la diversidad del mundo y del ajetreo de la acción. También el yo cartesiano se hará evidente una vez que se ha abandonado la diversidad mundanal; pero a diferencia de Montaigne, ese yo descubre una identidad que le sitúa por encima de cualquier contradicción.

1 En interesante hacer notar que, si bien Descartes insiste en que él no quiere reformar el saber de los demás, sino tan sólo él suyo mismo, las contradicciones sobre este punto en el Discurso permiten sospechar que la reforma que Descartes pretendía llevar a cabo se iniciaba con él ciertamente, pero el alcance que pretendía era universal. De ahí que sus fórmulas en este punto, a diferencia de las de Montaigne, parecen sugerir muchas veces lo contrario de lo que afirman. 
Navarro analiza largamente esa necesidad de retiro que acompaña a Montaigne (Navarro, 2007, pp. 47-82). El yo montañista está encarnado y atrapado en la acción del mundo. Una acción que ese yo experimenta más como acontecimiento que le sucede que como algo dirigido por él, no se siente agente protagonista. Ese estar volcado pasivamente hacia lo externo hace que el hombre que actúa no ejercite su libertad, ni la aprenda a través de su acción, sino más bien que continuamente la ceda ante otros reclamos: la riqueza -en el caso del hombre de negocios-, la gestión del bien común ante el que se sacrifica la moral -en el caso del político-, la acción bélica -en el caso del guerrero- y la adquisición de conocimientos que nada aportan a la persona salvo la gloria externa que el mundo otorga -en el caso del hombre erudito. Es el peligro del hombre ajetreado: la exterioridad hace que perdamos la interioridad, por eso Montaigne inicia un retiro donde poder recuperarla.

Ahora bien, ese retiro es mundano. La vuelta a la interioridad no tiene como motivo el conocimiento del yo en contraste con la mirada divina, al modo agustiniano o de los místicos. Lo que busca Montaigne es averiguar hasta qué punto el yo liberado de lo externo cambiante encuentra su libertad en sí y alguna identidad posible. Como se apuntaba, la experiencia montañista es casi peor en el retiro que en medio del mundo. El hombre retirado, Michel de Montaigne, se experimenta extraviado, perdido, cambiante continuamente en su juicio, ¿cómo ordenar la acción desde un juicio tan inestable e inseguro? El hombre ajetreado ha perdido el interés por la verdad, pero tampoco cabe hallarla en el retiro. Montaigne -quien no abre ninguna vía mística para la interioridad-decide aceptarse como es, con todo lo que haya en él de imperfección y de contradicción. Opta por el conservadurismo moral, se adapta al mundo con sus leyes y costumbres, antes de que el mundo se tenga que adaptar a él. La interioridad ya no es lugar de encuentro con lo divino, sino el espacio donde el hombre experimenta de un modo radical su profunda nulidad. Por eso se precisa salir nuevamente de esa interioridad y recuperarse a sí mismo a través de los otros. Esa vuelta al mundo, que Montaigne cumple en su vida, le permite aprender a disfrutar de los pequeños placeres mundanos y, en comercio con los otros, hacer vulnerable sus propios juicios para poder aceptar lo extraño a sí.

El yo montañista alcanza más humillación cuanto más prolongado es su retiro. Pues el retiro revela lo falible de nuestra condición humana: somos incapaces de aprender lo que las cosas son, la realidad siempre se nos hace presente a través de los sentidos y eso mismo hace que no podamos aprenderla en lo que ella tiene de verdadero y de esencial. No haya ese yo-que se mira a sí mismo-medios objetivos y comunes a los hombres para alcanzar verdadero conocimiento de la realidad: «nuestro juicio natural no distingue con claridad lo que examina» (Essais II, XII, p. 545). El juicio es diverso de un hombre a otro -concluye Montaigne-, luego no lo hemos alcanzado según el mismo medio. 
Si la realidad es la misma para todos, pero el juicio no, entonces el problema está en el sujeto que conoce; más en concreto: nuestro conocer es problemático siempre porque está mediado por la corporalidad sensible, parte constituyente de ese yo: «nuestra comprensión, nuestro juicio y, en general, las facultades de nuestra alma padecen con las continuas alteraciones del cuerpo» (Essais II, XII, p. 547). Los juicios, siempre diversos, causan en nosotros incertidumbre e inseguridad. Por eso insiste Montaigne: «recibimos las cosas según lo que somos y nos parecen, y este parecer nuestro es incierto y controvertible [...] ¿serán nuestros sentidos los que presten a los objetos diversas condiciones sin que los objetos en sí tengan más que una?» (Essais II, XII, p. 584) -recuérdese la polémica moderna en torno a las cualidades secundarias.

¿No se puede supera la barrera de los sentidos?, ¿acaso el alma puede alcanzar una hegemonía absoluta sobre el cuerpo? Si Descartes toma en serio a Montaigne e intenta ir más allá de él, debe procurar al menos dos cosas: primero, lograr un método que nos evite pasar por lo sensible; segundo, alcanzar una ciencia que nos ayude a controlar y dominar lo sensible, pues se presenta siempre como una amenaza para el conocimiento de la verdad. Que el método cartesiano pretenda un acceso directo a lo inteligible no es casual, como tampoco lo es que el propósito cartesiano primero y último sea hacernos dueños y poseedores de la naturaleza, de la res extensa, lo cual incluye al propio cuerpo. Volveremos sobre ello.

$\mathrm{Si}$ el retiro muestra que no somos capaces de conocernos a nosotros mismos de modo claro, ¿de dónde puede nacer -se pregunta Montaigne- la pretensión de conocer lo que sean las cosas o lo que sea el mismo Dios, sino de nuestro infundado orgullo y vanidad? No obstante, la conciencia de seres encarnados, sensibles, envueltos en el movimiento y el cambio son la mejor arma frente a esa arrogante vanagloria y toda pretenciosa autosuficiencia. El hombre es imperfecto y ninguna facultad haya en él que le permita superar esa condición. A ello contribuye también la meditación acerca de la enfermedad y la muerte. ¿Qué son éstas para Montaigne, sino las aliadas perfectas de la constatada y evidente nulidad y fragilidad humana, a la vez que un motivo de verdadera esperanza?

Montaigne había afirmado que la salud era una consideración principal en la vida de los hombres. La enfermedad y aflicciones embotan el alma y puede impedir la acción (Essais I, II, p. 16). Pero, por otro lado, es algo natural y común, se muere más por enfermedad que de vejez (Essais I, II, p. 312). El hombre no debiera temer la muerte, pues todo lo vivo participa de ella. El vulgo la ve con miedo y, por eso, no piensa en ella. A los ojos de Montaigne, no sólo se precisa pensar en ella, sino que además hay que aprender que no es un mal. Ante ella no cabe fingir. Es el momento donde se juzgan todos los actos de nuestra vida. Es preciso acercarse a la muerte para estudiarla e interpretar la vida desde ella. Nos enseña, entre otras cosas, que el mundo no nos retiene, 
de ahí que la muerte sea remedio para todos los males, pues con ella llega la seguridad, la indolencia, la impasibilidad. Nos librará de nuestra permanente contradicción. Sólo somos un hombre, lo que es para Montaigne sinónimo de irremediable imperfección.

La religión con su poderosa sabiduría viene en ayuda del hombre ante la muerte. No se ha de abandonar el mundo sin el consentimiento de quien nos ha puesto en él. Y además, no hay que pensar que estamos en este mundo sólo para nosotros mismos, sino para gloria de Dios y servicio de los otros. Quizá también por esta razón piensa Montaigne que la vuelta al mundo, con los otros, es obligada. Ha de salir de su retiro.

Frente a esas apreciaciones montañistas, se puede afirmar que las aspiraciones cartesianas muestran una gran estima en las capacidades de la razón humana, lo cual se traduce en poder sobre la naturaleza. Descartes nos asegura que siguiendo el nuevo método podremos llegar a «convertirnos en dueños y poseedores de la naturaleza» (Discours, AT, VI, p. 62). Esto es no sólo un voto de confianza a favor de la ciencia, cosa que le parecía a Montaigne imposible, fantasía y orgullo, sino prácticamente una promesa de salvación para los hombres, pues la ciencia puede llegar a liberarnos de la enfermedad y, quizá, de la muerte. Escribe Descartes: «lo cual es muy de desear -ser dueños y poseedores-, no sólo para la invención de una infinidad de artificios que nos permitirían gozar, sin ningún trabajo, de los frutos de la tierra y de todas las comodidades que hay en ella, sino muy principalmente también para la conservación de la salud, que es sin duda el principal bien y el fundamento de todos los demás bienes de esta vida, porque aún el espíritu depende tanto del temperamento y de la disposición de los órganos del cuerpo, que si es posible hallar algún medio para hacer que los hombres comúnmente sean más sabios de lo que hasta aquí lo han sido, creo que en la medicina es donde hay que buscarlos» (Discours, AT, VI, p. 62). La medicina misma -de la que tanto desconfiaba Montaigne- nos ayudará incluso en la tarea moral, ya que contribuirá a hacernos más sabios, más verdaderos, en la medida en que seamos menos dependientes de lo corporal, en la medida en que esté de modo seguro bajo nuestro dominio.

¡Qué distinto resulta el hallazgo cartesiano una vez retirado a sus cuarteles de invierno! Cansado de la variedad del mundo decide pasar por la escuela montañista con el deseo de abandonarla para siempre. Hace de la duda parte de un método que resuelva de modo definitivo y para siempre la fragilidad y nulidad de la condición humana. Tampoco el retiro cartesiano busca un conocimiento que tome en cuenta la mirada divina, en ese sentido es tan mundanal como el montañista. Quiere como Montaigne la máxima soledad, el máximo alejamiento de la tradición, de lo heredado, de lo aprendido. El resultado, sin embargo, es bien diverso: lejos de encontrar la humillación que se desprende de la nulidad de la propia condición, comparece un cogito, un alma indubitablemente existente, 
máximamente evidente, y liberado de lo corporal en el ejercicio de su acción más propia, es decir, en su pensar, donde no necesita de lo sensible. El cogito es una realidad permanente que se sitúa por encima de la contradicción a la que tan sólo podría conducir un pensar ejercido sin método, sin guía. El cogito cartesiano se alza confiado con una identidad que le define y que permanece inalterable y a resguardo de cualquier cambio. El cogito es inmortal. La muerte es asunto del cuerpo, no del alma. ¿Por qué no albergar la esperanza de poder alargar la vida corporal mediante el servicio de la medicina?

Descartes nos propone una especie de «paraíso en la tierra», sin ninguna relación con la sentencia dada al hombre en el Génesis (Kennington, 2004, p. 130). El mundo práctico cartesiano se traduce en beneficios alcanzados y dados al hombre con su sólo esfuerzo y saber. Se conseguirá remediar los malos efectos de la caída original. Aquellos bienes se vislumbran en las tres ramas de la ciencia que hacen referencia a lo práctico: la mecánica, la medicina y la moral. Lo primero nos asegura eficacia, bienestar, disfrutar de mil artilugios nuevos y nos ahorra esfuerzos. Lo segundo nos alcanza el fundamento de todos los demás bienes, como ya se ha mencionado: la salud. El tercero nos facilita disfrutar de lo más placentero de la vida a condición de aprender a usar de nuestras pasiones, en lugar de que sean ellas las que nos gobiernen. Según Kennigton, con Descartes la ciencia que conduce al hombre hasta la felicidad no es el tradicional estudio sobre la excelencia del alma, la ciencia moral y política, menos aún la teología, que muestra el camino para ganar el cielo -Descartes se ocupa de este mundo sin conexión con ningún otro posible-, sino la medicina, es decir, la ciencia del cuerpo (Kennington, 2004, p. 193). Por eso cuando Descartes comienza el estudio de las pasiones, nos presenta su trabajo como la investigación de un físico, a la que sigue una segunda parte enteramente moral.

La vuelta hacia el yo que se emprende con Montaigne y que va a inaugurar un nuevo modo de filosofar con Descartes presenta importantes diferencias entre nuestros autores. En Montaigne el yo es empírico y, en principio, particular. Montaigne se quiere conocer a sí mismo, por eso se investiga. No obstante, el estudio de su singularidad revelará la esencia misma del hombre: lo particular revela la condición humana. En Descartes el yo es metafísico, busca verdades seguras y desencantado de la diversidad externa decide investigar en él mismo con la esperanza de encontrar alguna verdad indubitable que le ayude a superar el escepticismo al que todo lo demás le invita. El cogito va a ser el punto de partida de su filosofía, aunque cederá su puesto de principio a Dios.

La diferencia es claramente apuntada por Navarro (2005, pp. 111 y 113): Montaigne nunca substancializa el yo, no es una instancia objetiva dentro del alma, el yo designa un sujeto que no puede ser objetivado. Si la búsqueda interior lleva a Descartes al éxito de encontrar una sustancia autosuficiente con una identidad definida para siempre, en ese sentido el fracaso montañista es claro, 
el yo sólo puede aspirar a ensayarse una y otra vez, y no deja de hacerlo porque nunca alcanzará algo así como una identidad definitiva. De todo lo anterior se desprende que el yo cartesiano parece representar el optimismo frente al pesimismo que acompaña el yo montañista. Al menos en un primer momento.

\section{El CULTIVO DE LA FILOSOFÍA}

Pero, ¿qué más se sigue de ese retiro que ambos emprenden? Algo se ha clarificado en cuanto al estatuto epistémico y ontológico del yo tanto en Montaigne como en Descartes, pero ¿qué decir de la filosofía?, ¿vale la pena cultivarla y esperar de ella el que nos guíe en la conducción de la propia vida? No hay que perder de vista que es eso lo que buscan ambos autores y que el análisis epistemológico y la metafísica - de corte nominalista en el caso de Montaigne y sustancialista en el caso cartesiano- son pasos previos y necesarios antes de desembocar en el uso práctico de la reflexión filosófica.

La sabiduría que Montaigne ha adquirido en el retiro voluntario que practica le ha confirmado que el hombre que filosofa inventa y finge. La facultad que más se ejercita al filosofar es la imaginación, pues no es más que fantasía lo que el hombre cree saber acerca de la realidad, ésta siempre permanece más allá del conocimiento que la razón particular de cada uno alcanza. Montaigne al encontrarse con los límites de la razón, ha encontrado que todo saber es mudable, parcial, especialmente el del filósofo. No cabe hallar normas universales de conducta. Por tanto, ¿qué podría servir de fundamento a la conducta del hombre? Unos mínimos prácticos sapienciales que comienzan con la tolerancia y coincidirán con la moral cartesiana (Chamizo, 1988, p. 74). Por tanto, la filosofía en tanto que ciencia es alejamiento de cualquier conocimiento real -aunque cabría plantearle a Montaigne la objeción de que tal afirmación exige cierto conocimiento de lo verdadero-; y como sabiduría queda reducida a unas pocas pautas, que más proceden de la costumbre y práctica social que del ingenio humano. Montaigne se conforma con lo probable, con lo verosímil para conducir la propia vida y cualquier tipo de seguridad en ese terreno y fuera de la certeza de la fe -con la que él no cuenta para desarrollar su saber, como tampoco hará Descartes más tarde- es quimérico.

El factum moral esencial del que parte Montaigne es el reconocimiento de la propia nulidad, flaqueza y miseria. Esa es la experiencia fundamental que hará que el hombre obedezca las creencias en las que ha nacido, sostenga las opiniones más moderadas y menos extravagantes, odie la arrogancia y la autosuficiencia, se aleje de las novedades, aprenda a sufrir lo que no se puede cambiar y se ajuste a las costumbres de su país. En síntesis, ese mínimo sapiencial montañista es el contenido de lo que años más tarde habría de ser la moral provisional del Discurso del Método. 
Una vez más es sorprendente el fruto tan distinto que obtiene Descartes de su retiro, está vez por relación a la filosofía. Para ello no hay que perder de vista el papel fundamental que juegan los sueños cartesianos del 10 de noviembre de 1619. Si bien es cierto que a veces se han querido presentar con cierto tinte místico esos tres sueños, es fácil advertir que se trata de un episodio psicológico más bien que de orden sobrenatural. Descartes se toma la molestia de interpretar los sueños y lo llamativo es que a partir de ese momento el gran genio francés descubre su tarea en el mundo: él será el encargado de reconstruir todo el edificio del saber. Descartes se sirve de una razón que interpreta en función de lo soñado. A raíz de ese episodio - tantas veces pasado por alto-él imagina, proyecta un sistema deductivo universal para conocerlo todo. Tanto Kennington como Grimaldi coinciden en señalar que la interpretación del sueño acentúa la superioridad de la imaginación frente a la razón (Kennington, 2004, p. 89; Grimaldi, 2006, p. 22). Remo Bodei insiste en la misma idea: la imaginación cartesiana será fuertemente excitada antes de que el cogito se descubra como sustancia pensante y su pensar como el atributo que la define (Bodei, 1995, p. 369).

El pensar cartesiano es en primera instancia un «pensar imaginario», no es un pensar puro, ni es el pensar del pensar de la razón pura. En la duda al final se descubre el pensar del pensar, y de ahí deriva la seguridad del cogito y de los pensamientos claros y distintos, pero el resto es un pensar mezclado de sensibilidad, por tanto, pensar imaginario, pensar que usa de las imágenes sensibles traducidas en hipótesis. En la técnica y en la moral hemos de tener en cuenta «hipótesis». Éstas serán verosímiles por lo que dice relación a la técnica y probables por relación a la moral. En el orden de la acción se ha de hacer «como si». El esquema verosímil de la técnica es de ensayo y de error, de modo que el esquema práctico de la moral también. Hay un paralelo entre uno y otro. Ahora bien, una vez que la imaginación ha sido utilizada para desencarnar al yo que piensa y que éste se descubre como sustancia existente, e igualmente ha cumplido - la imaginación- una función parecida en el desencanto del mundo, entonces es de nuevo limitada y reconducida al uso que le es más propio: el que tiene que ver con los asuntos de la vida.

Quizá eso explica las palabras que Descartes dirige a Elisabeth el 28 de junio de 1643: «Creo que es muy necesario haber comprendido bien, al menos una vez en la vida, los principios de la metafísica, por razón de que son éstos los que nos dan conocimiento de Dios y de nuestra alma, y también creo que sería muy perjudicial emplear a menudo el entendimiento en meditarlos, debido a que podría dejar vacante las funciones de la imaginación y de los sentidos; pero, lo mejor es contentarse con retener en su memoria y en su creencia las conclusiones que una vez se han sacado de allí, después emplear el resto del tiempo que se tenga para el estudio, en los pensamientos donde el entendimiento se conduce 
con la imaginación y los sentidos» (Correspondance, AT, III, p. 695). Descartes narra a Ellisabeth lo que años antes nos ha contado en el Discurso: en su solitario retiro él ha alcanzado a comprender que había que emprender una reforma del saber, y que esa reforma exigía poner entre paréntesis todo lo aprendido hasta el momento y buscar un nuevo punto de partida. Ahora bien, ese proyecto sólo lo puede llevar a cabo un solo hombre pues siempre es más perfecto -ejemplifica Descartes- lo que uno sólo realiza, que lo realizado entre varios. Ese hombre es precisamente Descartes quien ha descubierto el método adecuado para alcanzar conocimientos, que alejados de lo probable y lo verosímil, se muestran evidentemente verdaderos. Él, Descartes, ha dedicado un tiempo largo a la metafísica y ha alcanzado a comprender las dos grandes verdades que más nos importan: la inmortalidad del alma y la existencia de Dios. Una vez cumplida la tarea metafísica, lo que queda por hacer es vivir, esto es, actuar. Pero, ahí es donde comienzan los problemas que hacen tambalear el proyecto cartesiano, porque en la acción los pensamientos que tenemos no son claros y distintos, sino oscuros y confusos, pues son percepciones sensibles y pasiones.

Dicho de otro modo. Es preciso que el hombre dedique un tiempo a la especulación metafísica, pero no la mayor parte de su tiempo. La tarea metafísica es obra de la res cogitans, y en ese filosofar se descubren ideas innatas, ideas claras y distintas, dadas potencialmente al sujeto, a partir de ellas y siguiendo las reglas que Descartes adjudica a su método se despliega toda una ciencia deductiva, infalible y a priori que hará que se llegue al más alto grado de saber jamás alcanzado. La res cogitans es entendimiento puro. Ahora bien, en la vida cotidiana, el hombre no se puede desembarazar de su cuerpo, porque su corporalidad está comprometida en el transcurrir ordinario de la vida. El hombre que vive el día a día no es un metafísico especulativo, no es una res cogitans que no necesita de nada material para existir, sino que ese hombre que vive, que actúa y que no sólo especula, es unión de alma y cuerpo. Por tanto, así como en el terreno especulativo la búsqueda de la verdad lleva a ideas evidentes, que nos liberan del error; en el terreno práctico, la búsqueda de la verdad no desemboca más que en lo probable, pues allí donde lo sensible está presente, no hay evidencia. En la acción cotidiana hay que decidirse a actuar y la premura que exige la acción impide esperar a tener evidencias, las cuales siempre se alcanzan tras largas meditaciones, tal como Descartes ha hecho.

Llegados a este punto nos vemos obligados a reconocer que el optimismo cartesiano parece frustrado en la práctica. Ese proyecto de ciencia única ideado por Descartes parece que funciona sólo a medias. Parece haber superado el pesimismo montañista sólo en el terreno teórico, pero si para lo práctico no queda más que probabilidad, ¿dónde han quedado las promesas cartesianas de los pasajes del Discurso que apuntan lo que Descartes busca como fruto último de su saber? Descartes mismo nos confesó que «tenía un inmenso 
deseo de aprender a distinguir lo verdadero de lo falso para ver claro en mis acciones y andar con seguridad en esta vida» (Discours, AT, VI, p. 10). Justo para alcanzar ese propósito decidió abandonar las opiniones que hasta entonces había aceptado porque: «creí firmemente que por este medio lograría dirigir mi vida mucho mejor» (Discours, AT, VI, p. 10). Finalmente en la sexta parte del Discurso aludió a los frutos que se seguirían de su método: «hallar la solución de algunas dificultades pertenecientes a las ciencias especulativas o tratar de ordenar mis costumbres [...] es posible llegar a conocimientos muy útiles para la vida y que, en lugar de la filosofía especulativa enseñada en las escuelas, es posible encontrar una práctica por medio de la cual [...] convertirnos como en dueños y poseedores de la naturaleza» (Discours, AT, VI, pp. 61-62).

La filosofía práctica cartesiana, frente a la especulativa que se da en las escuelas y que aspira a sustituir, comprende la acción humana. Por un lado, la acción ejercida sobre lo que no es el hombre, esto es, la naturaleza, el mundo físico; por otro lado, la acción dirigida sobre lo que es el hombre, esto es, la unión de alma y cuerpo. La filosofía práctica en Descartes aspira a dominar la vida, tanto la del mundo natural como la propia; es decir, busca liberarla de la amenaza de la inseguridad y de la incomodidad del error. En definitiva, el espíritu humano aspira a ser independiente del mundo natural y que sea éste el que pase a depender de aquél (Grimaldi, 2006, p. 11) y no al revés, es decir, que sea la res extensa quien se ajuste a la res cogitans. Operación que exige la veracidad divina y que la acción en el orden técnico y en el orden moral sea reducida a utilidad.

Descartes busca la verdad y quiere que ésta acabe siendo útil al propósito práctico de su filosofía. La utilidad define la acción, tanto a nivel técnico como moral. La acción útil en lo técnico se traduce en dominio de la naturaleza; la acción útil en lo moral se traduce en la destreza que adquiere la voluntad -único agente, según Descartes- para que el cuerpo no nos disturbe, puesto que ¿qué distrae a la res cogitans sino lo que procede de la res extensa? Luego el hombre ha de aprender a dominar su cuerpo, igual que aprende a dominar la naturaleza. Ahí radica el fin de la filosofía cartesiana, y de ahí la importancia de la última obra publicada un año antes de su muerte.

Ahora bien, ese dominio sobre la vida exige pagar un precio muy alto. Conforme a lo que Grimaldi ha calificado como lógica de lo imaginario, el autor del Discurso establece las condiciones que ha de tener la realidad para que nada se resista a esa seguridad que está buscando: la realidad ha de excluir la contingencia, el azar, el accidente. Hay que diseñar la realidad según las condiciones que establece, antes que el método del saber, la imaginación cartesiana (Grimaldi, 2006, p. 65). Descartes antes de dar prioridad a la razón concede un papel protagonista a la imaginación: hagamos como si, imaginemos que, supongamos que... No se puede pasar por alto este modo de hacer. 
El afán de seguridad mueve la búsqueda cartesiana. Él había descubierto el método, las verdades metafísicas claras y distintas, que se deducían a partir de él, libres de probabilidad y dudas. Montaigne parecía derrotado. Sin embargo, Descartes no había redactado aún la tercera parte, no había enunciado las reglas de su moral provisional. Cuando éstas aparecen en la tercera parte del Discurso, Descartes nos dice: «basta juzgar bien para obrar bien, y juzgar lo mejor posible para hacer también lo mejor, es decir, para adquirir todas las virtudes y juntamente con ellas todos los bienes que pueden adquirirse» (Discours, AT, VI, p. 28). No se trata de juzgar según verdad, según evidencias infalibles, esas de tipo metafísico que excluyen lo probable y lo verosímil por considerarlo falso, se trata de juzgar precisamente según lo probable, único modo de hacer frente a la contingencia cambiante.

Descartes sabe que a la hora de actuar lo sensible compromete al hombre -unión de alma y cuerpo-, luego la evidencia racional -exclusiva de la res cogitans- no sirve como medida de la acción. Ante eso la probabilidad será tomada como medida para actuar. Dado que no se puede hacer con seguridad desde un juicio infalible, habrá que conformarse con hacer lo mejor según el juicio que la voluntad hace en cada momento. El divorcio de las facultades es evidente, como lo es el fracaso del proyecto cartesiano, realizable tan sólo teóricamente como si de una fábula se tratara.

El optimismo primero deja paso finalmente a un profundo pesimismo. La vida práctica exige siempre un retorno a la experiencia, la que primeramente fue desechada. La vía de la razón, la andan muy pocos -le confía a Elisabeth en 1646-, de modo que si bien sería deseable que los hombres fuesen todo lo razonables que se espera de ellos, de manera que sabiendo lo que deberían hacer, se pudiese juzgar lo que harán; sin embargo, ese deseo no se corresponde con la realidad, por eso cierra su carta con la siguiente sentencia: «más vale conducirse contando con la experiencia que con la razón, pues raramente se trata con personas perfectamente razonables» (Correspondance, AT, IV, p. 412). Descartes, al estar comprometido con lo práctico, no puede renunciar a aquello que está amenazado de contingencia y accidentalidad. De ahí que para los asuntos de la vida práctica, esto es, el transcurrir cotidiano y la técnica recomiende seguir la experiencia. La inseguridad y la incertidumbre acompañan a lo práctico. Aunque curiosamente, lo que Descartes ha estado buscando desde el principio era conducirse con seguridad. Al final, como se apuntó al comienzo, la vida moral cartesiana sigue bastante fielmente las pautas montañistas. 


\section{Conclusiones}

Retomamos la tesis del comienzo: ¿en qué se manifiesta la deuda de Descartes con Montaigne en moral? Montaigne busca en sus Ensayos como conducirse en la vida desde un punto de vista natural y no racional, marcando así una diferencia entre lo natural y lo racional, y habla de una condición humana débil e imperfecta. Descartes, entre sus primeras inquietudes, también busca estudiar la moral (Baillet, 1691, II, p. 111). En ese primer momento concibe la filosofía cómo un método de perfeccionamiento espiritual (Mesnard, 1936, p. 13) y seguro de no poder alcanzarlo al margen de la verdad, investiga cómo se ha de desarrollar el bien juzgar para el bien hacer. Su posición es que hay un sujeto potencialmente capaz de alcanzar la verdad desde su sola razón, una vez amueblada por la divinidad. Ahora bien, existe un divorcio entre razón y voluntad. La primera se dedica a investigar la verdad desde un punto de visto científico -según el método-, y la segunda busca cómo actuar del mejor modo frente a la contingencia probable. Muy pocos son los que se pueden dedicar a la primera tarea, quizá Descartes y alguno más -como se constata en la última parte del Discurso-, pero la mayoría de los mortales están más apremiados por el gobierno de su vida cotidiana como la tarea más urgente (Mesnard, 1936, p. 161). Por tanto, al final el hombre no científico, es decir, la inmensa mayoría, ha de atenerse a la utilidad y al pragmatismo de la moral provisional si quiere seguir los pasos de Descartes. Es decir, se ha de conformar con una moral que en su parte más esencial no difiere mucho de la montañista, y que al igual que ella está divorciada de la verdad en el orden práctico.

\section{REFERENCIAS BIBLIOGRÁFICAS}

ALQUIÉ, F. 1950: La découverte métaphysique de l'homme chez Descartes. París: PUF.

ARMOGATHE, J-R. 2000: «La première crise de la conscience européenne», en T. Gregory (ed.), Genèse de la raison classique de Charron à Descartes. París: PUF.

BAILlET, A. 1691: La vie de Monsieur Des-Cartes, vol. II. París: D. Horthemels.

BODEI, R. 1995: Una geometría de las pasiones. Miedo, esperanza y felicidad: filosofía y uso político. Barcelona : Muchnik.

BRUNSCHVICG, L. 1945: Descartes et Pascal, lecteurs de Montaigne. Neuchâtel: De la Baconnière.

CASALS PONS, J. 1986: La filosofia de Montaigne. Barcelona: Edicions 62.

CHAMIZO DOMÍNGUEZ, P. J. 1988: «La presencia de Montaigne en la filosofía del siglo XVII», en C. Baliñas Fernández, (ed.), Actas del Simposio sobre filosofía y ciencia en el Renacimiento. Santiago: Universidad de Santiago de Compostela, pp. 59-76. 
CHAMIZO DOMÍNGUEZ, P. J. 1984: La doctrina de la verdad en Michel de Montaigne. Málaga: Universidad de Málaga.

CHAMIZO DOMÍNGUEZ, P. J. 1982: «El Discurso del Método, de Descartes como ensayo», Aporía, vol. IV, n 15/16, pp. 69-83.

DESCARTES, R. 1996: Oeuvres de Descartes, vol. III, IV, V y VI, Charles Adam \& Paul Tannery (eds.). París: Librairie Philosophique J. Vrin.

FAYE, E. 1998: Philosophie et perfection de l'homme. De la Renaissance à Descartes. París: Vrin.

GADOFRE, G. 1987: «La chronologie des six parties», en N. Grimaldi y J-L. Marion (eds.), Le Discours et sa Méthode. París: PUF.

GILSON, E. 1976: Discours de la méthode. Texte et commentaire par Etienne Gilson. París: Librairie Philosophique J. Vrin.

GOUHIER, H. 1987: L'anti-humanisme au XVIIe siècle. París: Vrin.

GRIMALDI, N. 2006: Descartes et ses fables. París: PUF.

GRIMALDI, N. 1988: Six études sur la volonté et la liberté chez Descartes. París: Vrin.

KENNINGTON, R. 2004: On Modern Origins. Essays in Early Modern Philosophy. Oxford: Lexington Books.

LAPORTE, J. 1988: Le rationalisme de Descartes. París: PUF.

VV. AA. 1992: Montaigne et la Révolution philosophique du XVI siècle, Jacques Lemaire (ed.). Bélgica: Éditions de l'Université de Bruxelles.

LLINÀS BEGON, J. Ll. 1998: Formació, filosofia i escriptura en Montaigne: una lectura de De l'institution des enfans. Palma de Mallorca: Universitat de les Illes Balears.

MELEHY, H. 1997: Writing Cogito. Montaigne, Descartes and the Institution of the Modern Subject. Albany (N.Y.): State University of New York Press.

MESNARD, P. 1936: Essai sur la Morale de Descartes. París: Boivin \& Cie.

MONTAIGNE, M. (1962): Oeuvres complètes, Albert Thibaudet et Maurice Rat (eds.). París : Gallimard.

NÁJERA, E. 2003: Del ego cogito al vrai homme. La doble mirada de Descartes sobre el ser humano. Valencia: Universidad Politécnica de Valencia.

NAVARRO REYES, J. 2007: Pensar sin certezas. Montaigne y el arte de conversar. Madrid: Fondo de Cultura Económica.

NAVARRO REYES, J. 2005: La extrañeza de sí mismo: identidad y alteridad en Michel de Montaigne. Sevilla: Fénix.

RODIS-LEWIS, 1995: Descartes. Biographie. París: Calmann-Lévy.

THWEATT, V. 1980: La Rochefoucauld and the Seventeenth Century. Concept of the self. Ginebra: Librairie Droz.

TOULMIN, S. 2001: Cosmópolis. El trasfondo de la Modernidad. Barcelona: Península. 
RAQUEL LÁZARO es Profesora Adjunta de Historia de la Filosofía Moderna y Ética es el Departamento de Filosofía de la Universidad de Navarra.

\section{Publicaciones:}

La sociedad comercial en Adam Smith: Método, Moral, Religión. Eunsa, Pamplona, 2002.

«El escepticismo de Montaigne, ¿filósofo moderno o postmoderno?», en Paideia. Actas del II Congreso de la Sociedad Académica de Filosofía, Santiago de Compostela: Publicaciones Universidad de Santiago de Compostela, 2005, pp. 115-129.

Línea de Investigación:

Las pasiones en la filosofía moderna francesa y su relación con la ilustración escocesa.

Dirección Postal:

Depto. de Filosofía, Ed. de Bibliotecas, Universidad de Navarra, 31080 Pamplona, Navarra.

Direccióne-mail:rlazaro@unav.es 